\title{
La gestión social en proyectos de vivienda de interés social ${ }^{\star}$
}

\begin{tabular}{|c|c|c|}
\hline Fecha de recepción: 31 de MARZO de 2015 & Fecha de aceptación: 19 de julio de 2016 & isponible en línea: 30 de octubre de 2016 \\
\hline \multicolumn{3}{|l|}{ Laura Salamanca } \\
\hline Doctorado en Ingeniería de Proyectos & Universidad Tecnológica de Panamá & Isalamanca@corporacionresponder.org \\
\hline
\end{tabular}

Resumen El presente trabajo pretende el diseño de una metodología, cuyo objetivo principal es construir un modelo de convivencia urbana, a partir de generar un cambio cultural desde el hábitat de la población vulnerable de los proyectos de vivienda bajo el régimen de propiedad horizontal. Esta metodología puede ayudar en la construcción bajo el principio de corresponsabilidad, de conjuntos sostenibles a corto, mediano y largo plazo, en lo social, lo ambiental, lo económico y lo administrativo. Teniendo en cuenta la necesidad de verificar la hipótesis planteada, se decidió utilizar como herramienta estadística y cuantitativa el diagnóstico socioeconómico de 868 familias pertenecientes a dos conjuntos residenciales construidos para población vulnerable: uno para 100 familias en Lima (Perú), denominado Conjunto Residencial Los Ceibos; y otro para 768 familias, ubicado en el municipio de Soacha en Colombia. Los resultados de la aplicación de la metodología fueron exitosos como se demuestra en el presente artículo.

Palabras clave acción colectiva; mantenimiento de propiedad común; propietarios de bajos ingresos; propiedad horizontal 


\section{Social Projects Management Income Housing}

Abstract This project to design a methodology whose main objective is to build a model of coexistence, from a cultural change from the habitat of vulnerable people in housing projects under the horizontal property regime, so which can help in the construction of social, environmental, economic and administratively sustainable sets short, medium and long term, under the principle of shared responsibility.

Given the need to verify the hypothesis was decided to use as statistical and quantitative tool socioeconomic diagnosis of 868 families from two residential complexes built for vulnerable population, one for 100 families in Lima (Peru) called Residential Los Ceibos and other to 768 families in the municipality of Soacha in Colombia. The results of the application of the methodology were successful as demonstrated in this article.

Keywords collective action; common property maintenance; horizontal property; low-income homeowners

\section{Gestão social na habitação social projectos de interesse}

Resumo Este trabalho tem como objetivo projetar uma metodologia cujo objetivo principal é construir um modelo de coexistência na cidade, a partir de uma mudança cultural a partir do habitat de pessoas vulneráveis nos projectos habitacionais em regime de propriedade horizontal, de modo o que pode ajudar na construção de conjuntos sociais, ambientais, econômicos e administrativamente sustentáveis de curto, médio e longo prazo, com base no princípio da responsabilidade partilhada.

Dada a necessidade de verificar a hipótese foi decidido usar como ferramenta de diagnóstico socioeconômico estatística e quantitativa de 868 famílias de dois complexos residenciais construídos para a população vulnerável, um para 100 famílias em Lima (Peru) chamado Residencial Los Ceibos e outros 768 famílias do município de Soacha, na Colômbia. Os resultados da aplicação da metodologia foram bem sucedidos como demonstrado neste artigo.

Palavras chave ação coletiva; manutenção da propriedade comum; os proprietários de baixa renda; condomínios 


\section{Introducción}

Con esta investigación realizada en dos conjuntos residenciales ubicados en Lima y Soacha, que fueron escogidos por pertenecer a población reubicada por habitar en zonas de alto riesgo con un alto nivel de vulnerabilidad, pretendo el diseño de una metodología cuyo objetivo principal es construir un nuevo modelo de convivencia en la ciudad, a partir de generar un cambio cultural desde el hábitat de la población vulnerable de los proyectos de vivienda bajo el régimen de propiedad horizontal. Con esto se puede ayudar en la construcción de conjuntos residenciales, que a corto, mediano y largo plazo sean sostenibles en lo social, lo ambiental, lo económico y lo administrativo, bajo el principio de corresponsabilidad de sus residentes.

Los gobiernos locales se han visto en la necesidad de realizar la reubicación de familias en conjuntos residenciales sometidos al régimen de propiedad horizontal. Teniendo esto en cuenta, como hipótesis de trabajo consideré dar respuesta a una pregunta inicial: ¿Los problemas habituales de convivencia que enfrentan estas familias al ser reubicadas en los conjuntos residenciales o edificios bajo el régimen de propiedad horizontal, pueden disminuirse si se realiza una intervención psicosocial en las comunidades residentes en los mismos?

La presente investigación, muestra una alternativa innovadora que busca dar respuesta a esta necesidad de convivencia en la ciudad. En la primera, parte desde una perspectiva teórica, que contiene la revisión bibliográfica, encontramos un recorrido histórico por la creación de la propiedad horizontal en el mundo y en particular en Colombia. Luego analizaré, desde el punto de vista de la psicología, los aspectos psicosociales que intervienen en el proceso de socialización tales como la cultura de transgresión de la ley y los valores morales (ese conflicto interminable del ser entre la ley y el deseo), así como los arquetipos que encontramos en la propiedad horizontal. En la segunda parte, se aborda el diagnóstico socioeconómico de 868 familias de los dos conjuntos residenciales donde se realizó el trabajo de campo, el cual permitió unir el conocimiento teórico con una información valiosa del perfil socioeconómico de las familias que habitan en viviendas de interés social. Esto llevó a formular una metodología para la gestión social en vivienda de interés social con aplicación universal.

Si los investigadores sociales proponen metodologías de trabajo social, en los que la formación y capacitación comunitaria sean los ejes centrales, es posible generar un nuevo modelo de convivencia en la ciudad al construir cultura ciudadana desde el hábitat, donde los habitantes adquieran un conjunto de herramientas actitudinales, comportamientos y reglas mínimas compartidas, y establecidas por ellos mismos, que les permita una sana convivencia y sentido de pertenencia con su comunidad. 


\section{La propiedad horizontal} y las relaciones de vecindad

La institución llamada propiedad horizontal tiene su origen en los pueblos antiguos, no nace en la era moderna. Con el crecimiento poblacional en las zonas urbanas generado por la migración de campesinos en la posguerra, y por la violencia y el terrorismo en Colombia y Perú específicamente, nos encontramos con un hecho cierto que debe cautivar la atención de los científicos sociales: entre el $70 \%$ y $80 \%$ de la población mundial habita en zonas urbanas. Por ejemplo, en una ciudad como Bogotá (capital de Colombia), el $65 \%$ de las construcciones se construyeron bajo el régimen de propiedad horizontal, y teniendo en cuenta el número de población que habita en ellas podemos calcular que la mayor parte de la población vive bajo este régimen.

Las legislaciones de diferentes países buscan regular esa forma especial de dominio denominada propiedad horizontal, en la que concurren derechos de propiedad exclusiva sobre bienes privados, y derechos de copropiedad sobre el terreno y los demás bienes comunes. Este régimen tiene como fin garantizar la seguridad y la convivencia pacífica en los inmuebles sometidos a ella, así como la función social de la propiedad. Todas estas legislaciones tienen algo en común y es establecer una serie de derechos, deberes, obligaciones y prohibiciones que buscan atender a los principios orientadores de la propiedad horizontal, y que establecen un mecanismo del debido proceso para llegar a sancionar o multar a los infractores.

Para el caso colombiano la Ley 675 de 2001 establece cinco principios orientadores en su Artículo 2, a saber: 1) función social y ecológica de la propiedad; 2) convivencia pacífica y solidaridad social; 3) respeto de la dignidad humana;
4) libre iniciativa empresarial; 5) derecho al debido proceso.

En términos generales, en la revisión realizada en las diferentes legislaciones, reglamentos de propiedad horizontal, reglamentos internos generales y manuales de convivencia de los conjuntos residenciales de Colombia y Perú, se tienen en cuenta estos principios orientadores y se establecen una serie de deberes y prohibiciones que podemos resumir en: 1) actividades no permitidas; 2 ) actividades inmorales; 3) actividades incómodas.

Vemos entonces cómo desde el marco normativo se hace necesario regular las relaciones de vecindad. En todos los segmentos socioeconómicos existen graves problemáticas de convivencia, la población que inicia una nueva vida en su vivienda propia bajo el régimen de propiedad horizontal carece de una cultura de derechos, deberes, obligaciones y prohibiciones que regulen su vida en comunidad. Esta situación, para los hogares con menos ingresos, se convierte en una gran dificultad para garantizar el sostenimiento de su único patrimonio.

Una reciente investigación del Centro de Estudio y Análisis en Convivencia y Seguridad Ciudadana (CEACSC) adscrito a la Secretaria Distrital de Gobierno de Bogotá (SDG), nos muestra los comportamientos, y problemas de convivencia y relaciones de vecindad que más afectan la tranquilidad de las personas que habitan en conjuntos residenciales o edificaciones bajo el régimen de propiedad horizontal en la ciudad.

La investigación del CEACSC se hizo a partir del análisis de las 1.428 contravenciones presentadas en el año 2014. En el año 2013 se presentaron 935; es decir, tenemos una variación de 493 que equivalen a un aumento del $52,73 \%$, las cuales fueron querellas presentadas ante las diferentes inspecciones de Policía de la ciudad, 532 de ellas, 
que equivalen al $37 \%$, corresponden a amenazas, insultos y agresiones físicas, que comparadas con las 376 presentadas en el año 2013 muestran un aumento del $41 \%$.

La segunda contravención que se registra con mayor frecuencia entre los residentes es el ruido excesivo con 464 casos, es decir el $33 \%$, que comparado con las contravenciones presentadas en el 2013 por esta misma razón (250 casos), se incrementó el $86 \%$.

Otros de los problemas habituales de convivencia que muestra el estudio son: manejo y tenencia inadecuada de animales o mascotas (310 contravenciones correspondientes al 21,7\%), basuras y malos olores (303 contravenciones correspondientes al $21 \%$ ), uso inadecuado de zonas comunes $(74$ contravenciones correspondientes al $5 \%$ ), ruidos y malos olores producidos por mascotas (55 contravenciones equivalentes al $4 \%$ ), y excrementos sin recoger o depositados en lugares inadecuados (35 contravenciones equivalentes al 3\%).

El análisis causal que hace el estudio referencia que la mayor causa de la problemática de convivencia es que, quienes habitan en conjuntos residenciales o edificios, no están acostumbrados a convivir en comunidad. Rubén Darío Ramírez, director del CEACSC, dice: "En muchos casos, son personas que vienen de una vivienda unipersonal y se van a vivir a una multifamiliar, lo que conlleva grandes modificaciones en la cultura ciudadana y de convivencia”. Por otra parte, el director seńala, refiriéndose a los migrantes que vienen a la ciudad desde municipios más pequeños que:

Las personas que se vienen a vivir a Bogotá desconocen los procesos de convivencia que se desarrollan en una metrópoli de casi 8 millones de habitantes, los cuales son muy diferentes a los de una ciudad de 10 o 20 mil habitantes (El Espectador, 2015).

Este estudio evidencia que una alternativa de solución para esta problemática pública es la intensificación de campañas de cultura democrática, con el fin que los ciudadanos aprendan a resolver en paz sus conflictos, y que los constructores se involucren en la promoción de campañas de convivencia y cultura ciudadana.

El estudio del CEACSC solo nos muestra el análisis de las querellas documentadas en las inspecciones de Policía. Sin embargo, estoy completamente segura que esta cifra crece de forma exponencial cuando se suman los casos manejados por las administraciones, los consejos de administración y los comités de convivencia de los conjuntos residenciales, y que no llegan a constituir una querella.

Este fenómeno no corresponde a un caso aislado, los problemas de convivencia social y malas relaciones de vecindad existen en todos los países en mayor o menor proporción. Tal vez el lector de este artículo, si ha vivido en un conjunto residencial o edificio bajo el régimen de propiedad horizontal, sabe de qué estoy hablando.

Quiero a continuación mostrar el registro fotográfico que documenta situaciones de contravención a la normatividad vigente en propiedad horizontal. Este registro hace más contundente mi tesis acerca que no solo hay que tener una excelente normatividad sancionatoria, por decirlo de alguna forma, sino que se requiere un arduo trabajo de formación en cultura ciudadana.

Estas fotografías podrían haber sido tomadas en un solo país y encontraríamos las mismas situaciones en todos. 
Figura 1.

Mal manejo de residuos

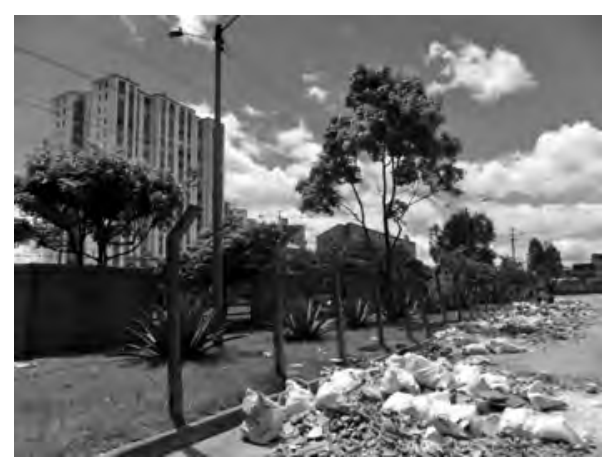

Fuente: elaboración propia

Figura 2.

Deterioro de un conjunto residencial en Ciudad de Panamá

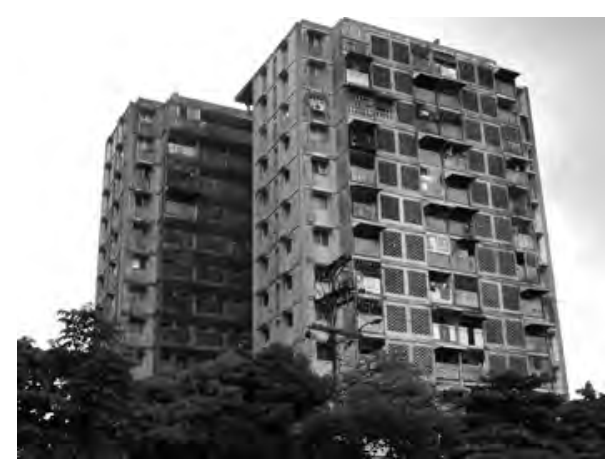

Fuente: elaboración propia
Figura 3.

Artículo diario El Espectador

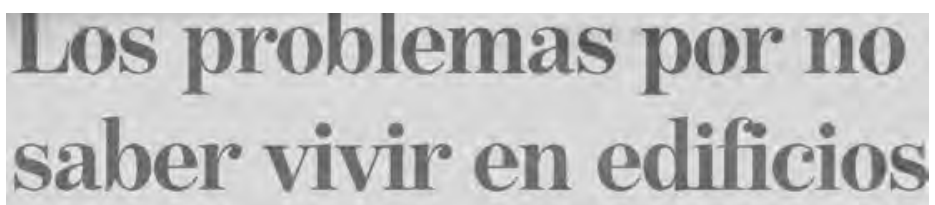

'Nuevos vecinos' provocan más conflictos dentro de los conjuntos.

Riñas, amenazas, agresiones y
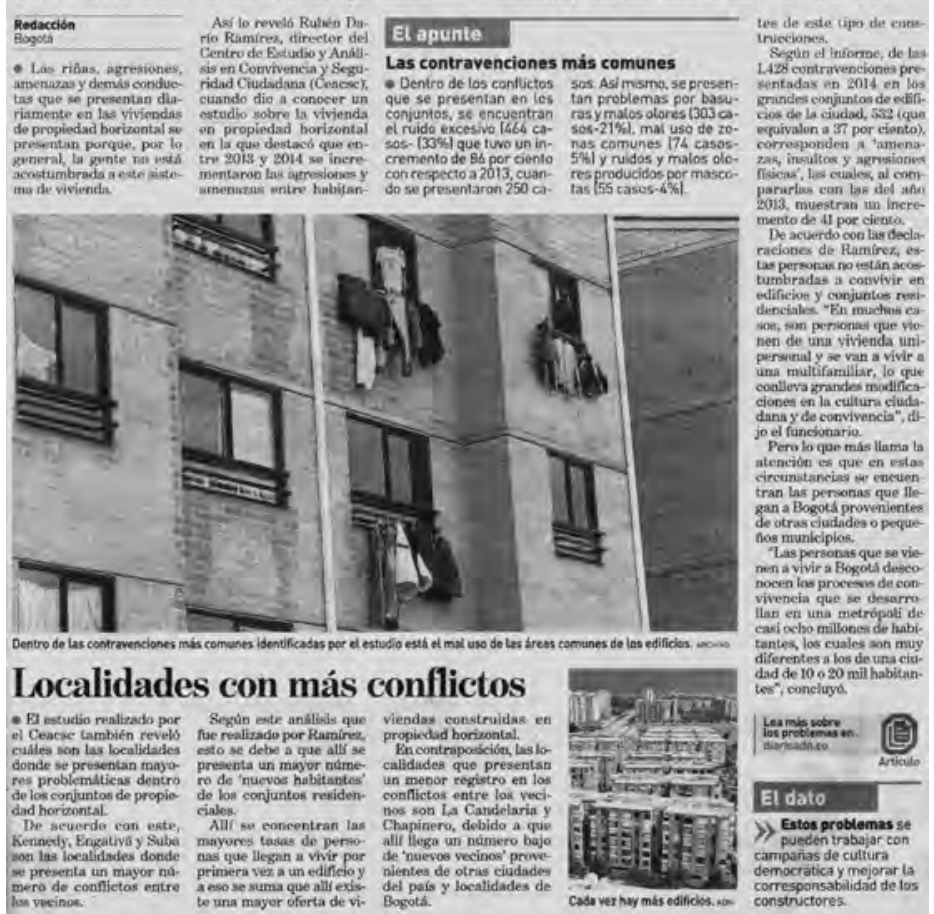

Fuente: El Espectador (2015)
Después de analizar a la comunidad de los dos conjuntos donde se desarrolló la investigación (Conjunto Residencial Acanto ubicado en el municipio de Soacha y conjunto residencial Los Ceibos ubicado en la ciudad de Lima) concluyo que es necesario diseñar programas de acompañamiento social cuyo objetivo sea generar cultura ciudadana en los habitantes de edificios o conjuntos residenciales bajo el régimen de propiedad horizontal.
Así, la presente investigación plantea una propuesta metodológica que busca dar respuesta a esta problemática, no sin antes realizar un análisis psicosocial de los factores que influyen en la cultura transgresora de las normas de convivencia en los conjuntos residenciales. Sin una investigación psicosocial que evidencie qué es lo estructural en el comportamiento humano en condominios, faltan elementos para que la ciencia social pueda establecer alterna- 
tivas de intervención en el marco de la cultura ciudadana.

En un conjunto residencial, los individuos son socios de personas que no conocen, y con ellas deben compartir zonas comunes que le pertenecen a todos los copropietarios. Si tenemos en cuenta que las relaciones humanas son conflictivas por naturaleza (basta decir que los problemas interpersonales son comunes incluso entre miembros de una familia), es más probable que se generen conflictos entre vecinos que se desconocen entre sí, pues hay menos tolerancia.

En cada edificio o conjunto habitan personas de diferentes orígenes y culturas, que llegan a vivir en comunidad trayendo consigo las costumbres que han adquirido en su historia de vida, pero lo característico de la propiedad horizontal es que cada propietario también comparte sus zonas comunes con otros copropietarios, que se convierten en vecinos, por lo que es evidente que existe una estrecha relación entre el individuo-propietario y su comunidad-vecinos. La psicología social se ocupa del estudio de la influencia del individuo en la sociedad y viceversa, por lo cual iniciaremos con un tema ampliamente estudiado por la psicología social como es el proceso de socialización del ser humano.

\section{La socialización}

Cualquier edificio o conjunto residencial en una ciudad moderna puede convertirse en un escenario sin igual para observar la diversidad de características culturales, sociales o económicas de las personas que habitan en la ciudad, en sentido reducido, y en el país, en sentido amplio. Con esto pretendo decir que en un pequeńo socio ecosistema como es un conjunto residencial, se puede analizar la repetición de formas de socialización y relacionamiento que también suceden en un macro socio ecosistema como la ciudad o el país. En un edificio o conjunto encontramos al vecino escandaloso, a la vecina entrometida, al colaborador, al problemático. Cada uno con una profesión u oficio distinto: profesionales, técnicos, sin educación, etc. El que viste bien, el que viste estrafalariamente, el alto y rubio, el bajito y moreno, el delgado, el gordo, en fin, vecinos hay de todas las características posibles.

Cada uno de ellos se siente sujeto de acción, aunque este sentimiento puede ser de distinta calidad y contenido. Seguramente cada uno se refiere a sí mismo como "yo" y se identifican y se ven a sí mismos como personas; en pocas palabras, somos iguales pero a la vez somos diferentes. Si se les pregunta quiénes son dirán su nombre, seguramente su apellido y ańadirán lo que son y lo que hacen, es ahí en donde puede notarse una identidad que los distingue como personas y los diferencia de cualquier otro individuo.

Pero también tienen en común que se sienten parte de una sociedad, se sienten copropietarios del conjunto residencial, se sienten bogotanos o limeños, colombianos o peruanos, aunque sentirse parte de esa sociedad puede tener un sentido diverso para cada uno de ellos. Esta diversidad de personas nos muestra que, en medio de la diferencia, cada una de ellas tiene una identidad, un yo propio que las hace diferentes, así como un vínculo social que las une, una referencia común que los identifica y al mismo tiempo los hace miembros de una misma comunidad, en este caso la vivienda, los hace miembros de la comunidad del edificio o del conjunto residencial.

La pregunta es ¿̇e dónde proviene esa doble faceta de ser que nos hace diferentes, pero a la vez iguales, nuestra identidad diferenciadora y nuestra identidad vinculante, el yo personal y el yo social? La respuesta es: de los procesos de socialización. 
Psicólogos y sociólogos entienden el concepto desde una perspectiva diferente. Para los sociólogos es un proceso por el cual una sociedad $\mathrm{u}$ orden social logra sobrevivir y perpetuarse, transmitiendo a los nuevos miembros las normas y principios necesarios para que el orden social continúe. La socialización cambia así a la persona. En términos de Freud (1970) la va transformando del principio del placer al principio de realidad, la va haciendo previsible respecto al orden social y ajustada a sus objetivos, lo que permite el funcionamiento normal de ese sistema. Es decir, si todas las personas de un conjunto residencial o edificio tienen un proceso excelente de socialización en lo que respecta a los temas de urbanidad, cultura ciudadana y principios básicos de convivencia, no existirían todos los problemas mencionados anteriormente.

Para los psicólogos la socialización es el proceso mediante el cual los individuos adquieren determinadas habilidades necesarias para adaptarse y progresar en una sociedad, es decir, desde esta perspectiva el individuo cambia a fin de poder sobrevivir en la sociedad. Sociólogos y psicólogos ven el proceso de cambio que se da en los individuos, pero donde unos enfatizan la necesidad del sistema establecido en el orden social, los otros subrayan la necesidad del individuo.

En el diseño de la metodología planteada en esta investigación, me aparto de estas dos posturas por considerar que lo ideal es integrarlas, y me uno al planteamiento de Ignacio Martin Baro (1997) para entender que la socialización es un proceso psicosocial en el que el individuo se desarrolla históricamente como persona y como miembro de una sociedad. En su definición de socialización Martin Baro, sostiene tres afirmaciones: 1) la socialización es un proceso de desarrollo histórico; 2) es un proceso de desarrollo de la identidad personal; es un proceso de desarrollo de la identidad social.
El autor sostiene que la socialización constituye un proceso de desarrollo que, se caracteriza por su concreción temporal y espacial. No es un proceso mecánico, inmutable, prefijado solamente por mecanismos genéticos o biológicos, su carácter es definido por las circunstancias propias de cada situación histórica concreta.

Por lo anterior, para analizar los procesos de socialización de los individuos que habitan en edificios o conjuntos se requiere examinar como variables fundamentales en qué sociedad, en qué clase social, en qué grupo, en qué época, en qué situación, en qué coyuntura han tenido lugar estos procesos. En el trabajo de campo, donde se implementó la metodología propuesta, se evidenció en el caso colombiano, luego de preguntar a todas las familias en los diferentes talleres realizados, que todas las familias del conjunto han sido víctimas del conflicto armado y la violencia en Colombia que lleva 130 años desde la Guerra de los Mil Días, y aún continúa. En Perú el problema no es tan grave, la época del terrorismo de la década de los ochenta terminó dejando una generación afectada con secuelas del terrorismo, pero las nuevas generaciones solo saben lo que les han contado, de hecho existen personas que ni siquiera conocen qué sucedió en esa época.

Que la socialización sea un proceso histórico quiere decir que no es de carácter formal y aunque es importante examinar cómo se trasmite la información, más importante aún es examinarla. No es lo mismo transmitir principios básicos de convivencia social, que transmitir las multas y sanciones por la trasgresión de los mismos, aunque los unos y los otros se pueden adquirir por aprendizaje social. Lo que recibe el individuo con lo primero es una conciencia de que debe ser el vecino que desea tener, y lo que recibe con lo segundo es que si lo descubren siendo infractor, seguramente lo van a multar o sancionar. 
Al ver la socialización como un proceso de desarrollo de la identidad personal, cada individuo va configurándose como persona. El individuo y la sociedad no son dos entidades independientes, no existe el individuo imperfecto y la sociedad perfecta, son transversales, la persona se va configurando en y frente a la sociedad, como afirmación de su individualidad particular. La sociedad no es entonces algo externo a la identidad personal, es elemento configurador de su ser personal. Por esta razón, cuando se constituye un edificio o conjunto en propiedad horizontal, y llegan sus habitantes, se configura una nueva sociedad, por lo cual es el momento adecuado para que se establezcan relaciones basadas en principios mínimos de interlocución, autorregulación, solidaridad, cooperación y negociación.

Por último, la socialización es un proceso de desarrollo de la identidad social. Marca al individuo con el sello propio de la sociedad a la cual forma parte, señala una pertenencia desde las raíces más profundas a la estructura social de la cual forma parte el individuo, no hay identidad personal que no sea al mismo tiempo identidad social. Los procesos de socialización pueden continuar a lo largo de toda la vida, de hecho es la base fundamental para estructurar la metodología aquí propuesta. La socialización de una persona progresa a partir del lenguaje, la moral y de la sexualidad. Así desarrolla una identidad personal en circunstancias y situación específicas.

\section{Socialización moral \\ (moralidad y control social)}

Establecer que un comportamiento es 'bueno' o 'malo', supone confrontar los intereses personales con los intereses sociales, la conveniencia de un grupo con los deseos de una persona, el principio de realidad frente al principio del placer. La moral pretende regular los comportamientos con el fin de establecer un equilibrio entre la satisfacción del individuo y los intereses del colectivo. Esta dicotomía entre individuo y grupo constituye el problema recurrente de la vida social, en que la moral y las normas de cada grupo social tratan de dar una respuesta concreta. La normatividad moral considera que los comportamientos son buenos cuando pretenden generar ese equilibrio entre lo individual y lo colectivo.

Esa existencia moral que se materializa en los reglamentos y manuales de convivencia en la propiedad horizontal me generan preguntas, desde la naturaleza misma de los principios y los criterios involucrados, hasta la forma concreta como operan. Desde las últimas raíces de los imperativos morales, hasta las sanciones que afirman su vigencia social. Como psicóloga social me pregunto cómo y en qué medida la moral es parte de las personas que habitan un edificio o conjunto, y cómo opera la moral en el control del comportamiento de un copropietario y de una asamblea de copropietarios. Si queremos dar respuesta a esto, y generar una metodología que pueda generar cultura ciudadana, tenemos que tener en cuenta la socialización moral, que es sin duda, el proceso socializador por excelencia, ya que las normas definidoras del bien y del mal, y de los hábitos correspondientes, se materializa en un orden social. Mediante la adquisición de una moral el copropietario hace propios los principales mecanismos de control social de la propiedad horizontal.

¿Pero qué es control social? Talcott Parsons (1968) concibe el control social en contraposición a las tendencias que se apartan del orden de un determinado sistema, y lo define como "aquellos procesos en el sistema social que tienden a contrapesar las tendencias desviadas" (p. 197). Para el autor, el control social se refiere a un estado de equilibrio del sistema, lo que supone en lo social el funcionamiento de estructuras normativas (valores y normas sociales), y en lo individual la motivación hacia el conformismo social. 
Los mecanismos de control social actuarían entonces en la regulación de los roles sociales y en la motivación de los individuos hacia el desempeño de esos roles requeridos por el sistema. Es así, que la moral supone la interiorización del control social, a partir del proceso de socialización que integra armoniosamente al individuo con el orden del sistema dado. Constituye la capacidad de una determinada sociedad o grupo social para regularse así misma de acuerdo con sus propios principios y valores, se convierte en una capacidad del colectivo para autorregularse.

\section{Aspectos conceptuales y metodológicos}

Teniendo en cuenta la necesidad de verificar la hipótesis planteada en el presente trabajo, decidí utilizar como herramienta estadística y cuantitativa el diagnóstico socioeconómico de 868 familias pertenecientes a dos conjuntos residenciales construidos para población vulnerable en vivienda de interés social: uno para 100 familias en Lima (Perú), denominado Conjunto Residencial Los Ceibos; y otro para 768 familias, ubicado en el municipio de Soacha en Colombia.

La decisión de hacer estos dos análisis obedeció al interés por diseñar una metodología de gestión social que tenga aplicación universal o, por lo menos, en países en desarrollo como los latinoamericanos. El punto de partida fue elaborar un estudio haciendo uso de la Investigación-Acción Participativa (IAP) con las comunidades objeto de intervención, cuyos resultados permitían hacer una metodología ajustada y especial para este tipo de comunidades.

Se pretende en este trabajo el diseño de una metodología que realice un estudio de las condiciones internas (análisis de tipo de población y diferentes arquetipos) y externas (políticas públicas en vivienda y procesos de socialización) que tipifican realidades psicosocioculturales, políticas, económicas, administrativas, ambientales, tecnológicas y espaciales, que se relacionan de modo interdependiente, y que se expresan como los principales rasgos de una sociedad en un sistema social como lo es un conjunto residencial.

\section{Enfoque}

La propuesta de intervención promueve un enfoque holístico, integral y participativo, lo cual es una apuesta a largo plazo. Una negociación permanente y unos pactos entre los actores que se tendrán que modificar y verificar más allá del tiempo por medio de una evaluación expost. El desarrollo de una propuesta urbana reconoce que los cambios sociales no se producen de inmediato, y que estos incluyen el área de influencia del proyecto (comunidad receptora) de forma directa como indirecta. Por esta razón, la estrategia central se identifica con la participación de la comunidad, la cual inicia cuando se genera sensibilidad social y sentido de pertenencia hacia su edificio o conjunto.

Otro de los pilares fundamentales, y herramienta fundamental es el fortalecimiento de la institucionalidad. La amplitud del reto renovador exige, más allá del liderazgo que pueda ofrecer la metodología, que los organismos responsables de los aspectos sociales, ambientales, culturales, productivos y económicos asuman una gran responsabilidad para que el propósito municipal se cumpla. Es entender que la función de cada uno de los organismos y funcionarios se convierte en interdependiente, es decir, se hace necesaria una alianza con otros actores sociales e institucionales para transformar las condiciones de calidad de vida de esta población. Se requiere de la vinculación de la empresa privada, las ONG y otros. Es preciso establecer convenios con las diferentes ONG tanto de tipo social, de género, de juventud, entre otras. 


\section{Formación y capacitación}

Como eje transversal del modelo de gestión se encuentra la formación y capacitación por medio de la cual y por medio de la socialización, se busca un cambio cultural y una toma de consciencia en la población vulnerable y en los líderes que habitan en estos conjuntos residenciales. Esta formación y capacitación se realiza con una serie de talleres teórico-prácticos, que tienen como principio epistemológico el método dialéctico de la psicología social, la IAP y la gerencia social.

El método dialéctico visto desde la psicología social considera que la persona y la sociedad se constituyen mutuamente, sin que se pueda entender la una sin la otra. Para comprender los procesos ideológicos de una persona deberá examinarse la estructura social de la que es parte y viceversa. Por ello, decidí utilizar la IAP, dado que permite, durante el desarrollo del modelo de gestión, abrir espacios de acción y participación con la comunidad, generando sentido de pertenencia con su edificio o conjunto residencial.

En cuanto a la gerencia social da los principios para consolidar el capital social en la comunidad y, sobre todo, en los líderes para llevarles a ser artífices de su propia historia, generando una mejor calidad de vida en un conjunto residencial sostenible a corto, mediano y largo plazo en lo social, lo ambiental, lo económico y lo administrativo. El modelo de gestión contiene un programa de formación para todos los copropietarios y uno específico para la administración y líderes. En la Figura 4 se describe de manera detallada cada uno de los talleres de capacitación realizados con la población vulnerable. Anexo al presente trabajo se encuentran las presentaciones de todos los talleres.

Figura 4.

Esquema general del modelo de gestión social

CONOCIMIENTO

TÉCNICO

Y NORMATIVO

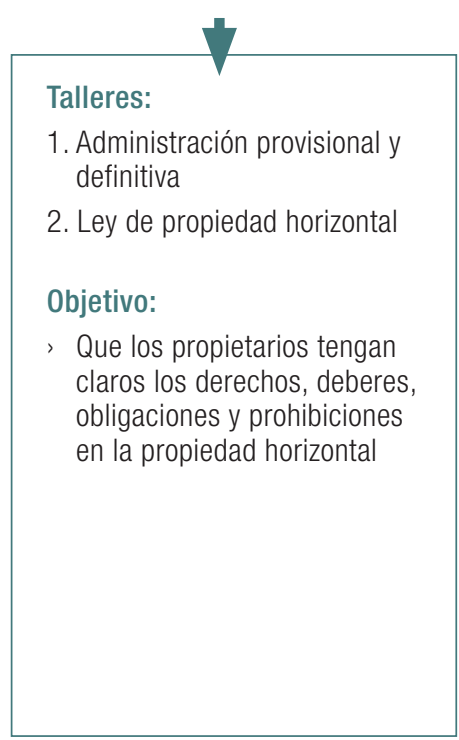

CONVIVENCIA SOCIAL

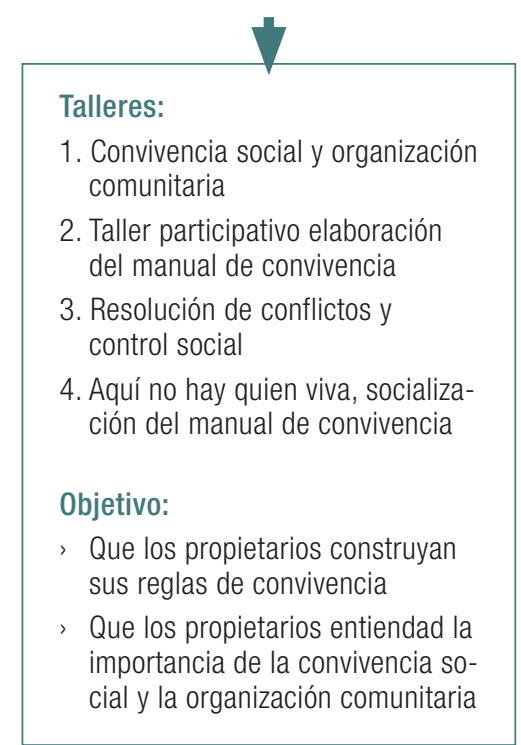

ADMINISTRACIÓN

$Y$ LIDERAZGO

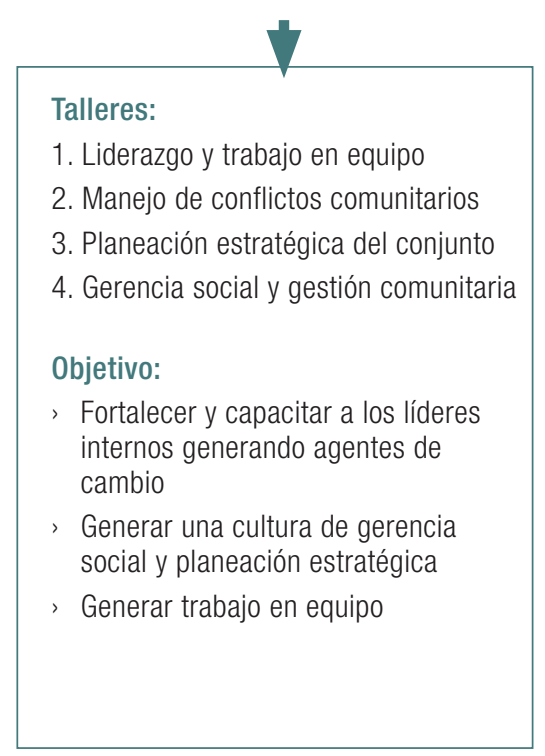




\section{Resultados}

Desde el marco teórico de la IAP y la gerencia social, con el cual construí el modelo de intervención en el Programa de Acompañamiento Social, se desarrolló el proceso de evaluación expost teniendo en cuenta la construcción de indicadores de gestión para medir los resultados alcanzados por el programa.

Con el fin de garantizar la continuidad y consolidación de los resultados alcanzados planteo el seguimiento constante a las juntas directivas o consejos de administración de los conjuntos estudiados, para monitorear los avances y dar directrices de ajustes si se requiere.

Evaluación expost de la metodología de gestión social en las 768 familias del conjunto residencial Acanto (realizada durante los meses de agosto y septiembre de 2014)

Para los indicadores se establecieron los siguientes rangos: $0 \%$, excelente; $1 \%$ al $5 \%$, muy bueno; $6 \%$ al $10 \%$, bueno; $11 \%$ al $15 \%$, aceptable; $16 \%$ al $20 \%$, regular; $21 \%$ o más, malo.

\section{Criterios o parámetros:}

\section{Indicadores de asistencia:}

El promedio de asistentes a los talleres fue de 730 personas, lo que nos indica que el porcentaje de inasistencia fue del $5 \%$, es decir que nuestro indicador es muy bueno en asistencia.

\section{Sostenibilidad económica del conjunto:}

Porcentaje de mora: 9,8\% (bueno).

Hasta la fecha la sostenibilidad económica del conjunto residencial ha sido buena teniendo en cuenta los ingresos económicos de las familias.

\section{Administración y organización:}

La administración del conjunto se organizó en su fase provisional con la constructora, y en su fase definitiva con la comunidad. Esta administración ha generado trabajo para la población del conjunto.

En términos generales la organización y administración está funcionando muy bien ya que han logrado establecer mecanismo de control que permiten no tener cartera morosa en el conjunto.

Cumplimiento de reglamentos y normas internas:

Porcentaje de incumplimiento: 1\% (muy bueno).

Incorporación a programas institucionales:

\section{Afiliación al Sisben:}

$\mathrm{Al}$ realizar el diagnóstico socioeconómico encontré que el $7,5 \%$ de la población a reubicar no tenía ningún cubrimiento en salud, razón por la cual se estableció como prioridad gestionar la afiliación colectiva al Sisben de la población sin cubrimiento.

Solicitamos el apoyo del municipio por intervención de la Secretaria de Salud, y con la encargada del Sisben se estableció el compromiso de realizar las afiliaciones de todas las familias de manera colectiva. Para esto se programó una brigada de afiliación en el marco del proyecto, con lo cual se cumplió el objetivo propuesto.

\section{Talleres y capacitaciones:}

Se gestionó una beca para los cinco mejores líderes de la población con el fin de capacitarlos en propiedad horizontal. El 1 de diciembre de 2012 se graduaron del mejor diplomado en propiedad horizontal que existe en Colombia, 
el cual fue dictado por el Colegio de Administradores de Propiedad Horizontal. Esta formación permite que con estos cinco líderes se pueda organizar la administración definitiva del conjunto.

Figura 5.

Líderes graduados en propiedad horizontal

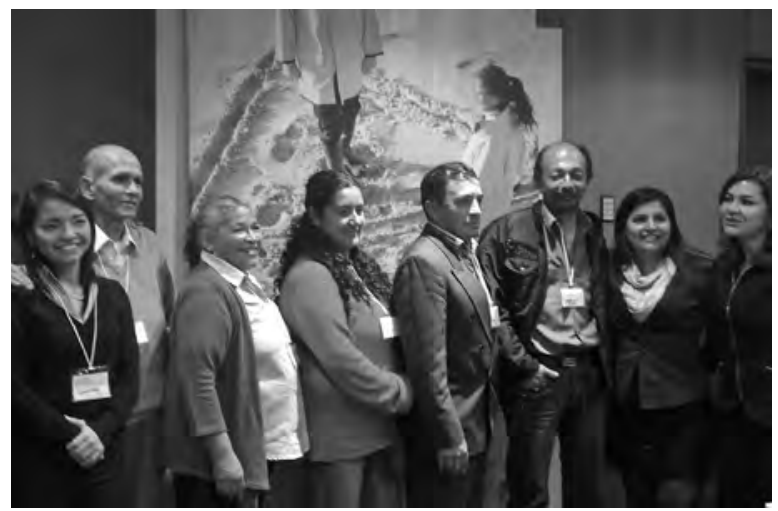

Fuente: elaboración propia

\section{Evaluación ex-post de la metodología de gestión social en las 100 familias del conjunto residencial los Ceibos (realizada durante los meses de junio y julio de 2014)}

\section{Indicadores de asistencia:}

El promedio de asistentes a todos los talleres fue de 90 personas, lo que nos indica que el porcentaje de inasistencia fue del $10 \%$, es decir nuestro indicador es bueno en asistencia.

\section{Sostenibilidad económica del conjunto:}

Porcentaje de mora: $0 \%$ (excelente).

Hasta la fecha la sostenibilidad económica del conjunto residencial ha sido excelente teniendo en cuenta los ingresos económicos de las familias.

\section{Administración y organización:}

La administración del conjunto es autogestionada, cada directivo del edificio se encarga de recaudar las cuotas de mantenimiento ordinarias y extraordinarias, así como y el pago de los servicios comunes.

El servicio de jardinería lo hace una persona discapacitada, copropietario del conjunto, y la limpieza la realiza una señora, también copropietaria del conjunto, que tiene un hijo discapacitado. Estas dos personas fueron contratadas por una empresa que prestaba estos dos servicios al conjunto, pero con mano de obra de la comunidad.

En términos generales, la organización y administración está funcionando muy bien ya que han logrado establecer mecanismo de control que permiten no tener cartera morosa en el conjunto.

\section{Cumplimiento de reglamentos y normas internas:}

Porcentaje de incumplimiento: $1 \%$ (muy bueno).

La comunidad logró apropiarse de los conceptos de la metodología de gestión, hacen control social y existe una sana convivencia.

Incorporación a programas institucionales:

\section{Afiliación al SIS:}

Al realizar el diagnóstico socioeconómico encontré que el $85 \%$ de la población reubicada no tenía ningún cubrimiento en salud, razón por la cual se estableció como prioridad gestionar la afiliación colectiva al SIS de la población sin cobertura.

Solicitamos en el mes de mayo de 2012 cita con el gerente de Desarrollo Social de la municipalidad y con la encargada del SIS, y se estableció el compromiso por parte de ellos de gestionar ante 
el Hospital de la Solidaridad la posibilidad de hacer la afiliación colectiva, pero que fueran totalmente subsidiados, ya que al ser propietarios de un departamento en condominio sus condiciones económicas cambiaban y ya no tenían derecho a tal subsidio.

Le explicamos a la encargada que era importante darles un tratamiento especial a estas familias ya que eran parte de un programa de reubicación, ella se comprometió a hacer todo lo que estuviera a su alcance para lograrlo. A la fecha ya realizaron la visita domiciliaria a todas las familias que están habitando el conjunto que no tienen ningún cubrimiento en salud, el informe de esta visita reportó que aproximadamente el $56 \%$ de la población iba ser aceptada con el subsidio del $100 \%$, y los demás debían pagar una cuota moderada que está al alcance de todos.

Logros de la junta directiva y los consejos de administración por medio de la metodología de gestión social

La metodología de gestión social se enfocó en promover que los nuevos vecinos se relacionen entre sí, influyendo de forma eficaz en el bienestar social, y ayudando a las comunidades a crecer y a fortalecer la democracia y los gobiernos locales, para lograr así administrar mejor la justicia y respetar los derechos humanos. Un objetivo de la metodología es consolidar la organización comunitaria con la finalidad que los ciudadanos se vinculen e involucren en la adopción de las reglas de convivencia que hayan pactado colectivamente y participen de las decisiones que se tomen. Con esto se busca generar sostenibilidad económica, administrativa y social de las nuevas comunidades.

Por medio de la implementación de la metodología se logró gestar cambios de comportamiento en los propietarios, así como la creación de redes sociales sólidas, que nos permiten citar como logros lo siguiente:

- La preservación de las áreas comunes por medio de la autogestión comunitaria.

, El control y adecuado manejo de los conflictos sociales.

- La creación de un fondo de contingencias, que sirve para pintar los edificios y áreas comunes, colocar casetas de vigilancia de material noble y realizar cualquier clase de arreglo para la conservación de los conjuntos.

- Vecinos concientizados sobre la importancia del pago de la cuota de mantenimiento, el servicio de agua y luz común.

- Vecinos que velan por el perfecto estado y cuidado de los bienes comunes como: mangueras contra incendios, extintores, luces de emergencia, ascensores, etc.

, La conformación de redes sociales con las juntas vecinales, serenazgo, comisarias, bomberos, municipalidad, empresas de servicios públicos, frentes de seguridad, etc.

, El mantenimiento constante del equipamiento.

- El establecimiento de los horarios para el acopio de residuos sólidos.

\section{Conclusiones}

A continuación, para concluir el presente artículo, se hace una recapitulación de los conceptos vistos y de los resultados obtenidos con la aplicación de la metodología.

Primero, en el recorrido histórico por la propiedad horizontal, vimos que esta forma especial de propiedad no es nueva, ni siquiera se creó en el 
último siglo, es una institución que data desde los pueblos antiguos con evidencia de su existencia desde el año 2000 a. C. Los problemas de vecindad vienen desde la misma creación de la propiedad horizontal porque son inherentes al ser humano.

La cuestión fundamental que nos convoca para intervenir desde la ciencia social en estas relaciones de vecindad, es que los problemas de vecindad y convivencia entre residentes en la propiedad horizontal se vienen incrementando exponencialmente en los últimos años, como lo demuestra el estudio presentado en el capítulo cinco. Este estudio realizado por el CEACSC (adscrito a la SDG) documenta los comportamientos y problemas de convivencia y relaciones de vecindad que más afectan la tranquilidad de las personas que habitan en conjuntos residenciales o edificaciones bajo el régimen de propiedad horizontal en la ciudad.

El estudio establece que las contravenciones presentadas por estas causas aumentaron entre el año 2013 y el año 2014 en un 52,73\%: las que tienen que ver con amenazas, insultos y agresiones físicas, mostraron un aumento del $41 \%$; las de ruido excesivo incrementaron en un $86 \%$ de un año a otro, solo por hablar de los dos más importantes. Pero igual sucede con los demás problemas habituales de convivencia como son: mascotas, manejo de basuras, parqueaderos, etc.

Mi tesis es que las problemáticas en las relaciones de vecindad en la propiedad horizontal son ya un problema de salud pública que deben ser analizadas y atendidas por los Estados con ayuda de científicos psicosociales. Máxime si tenemos en cuenta que con el transcurrir del tiempo en muchas ciudades latinoamericanas, la reorganización urbana se ha dado en la medida de su crecimiento, pero esta organización no ha sido proporcional ni equitativa con respecto al incremento de su población. El acelerado desplazamiento de personas a las grandes ciudades ha incrementado la población vulnerable que demanda de vivienda de interés social.

Por otra parte, la tendencia de diseño de conjuntos residenciales de varios edificios, va en aumento. Independientemente del sector económico y de la cultura, cuando las personas van a vivir en propiedad horizontal, surgen factores como los pagos de administración, la convivencia y otros cambios que se generan por el nuevo estilo de vida en altura. En los diferentes países de América Latina surge la inquietud por la administración de la propiedad horizontal. Las constructoras, al encontrarse con la necesidad de prestar servicios de administración, les es difícil ubicar compañías con experiencia en el sector. Son muy pocas las empresas de administración las que realmente realizan lo que prometen, en muchos casos aprenden en el camino, pues son muy pocas las que se han capacitado. Muchas empresas son informales y por eso terminan haciendo malos manejos y desfalcos en las cuentas de los conjuntos. Esto sumado a la inexperiencia de las juntas directivas o consejos de administración, genera que la población no mejore su calidad de vida con la vivienda propia, sino que, por el contrario, tenga nuevos problemas.

Cuando las personas llegan a habitar un conjunto residencial, no conocen a sus vecinos, cada una lleva a cuesta sus raices pulsionales, la historia de cada individuo, la forma en que ha elaborado su relación con otros y la estructuración de la personalidad que viene del esquema básico padre-madre-hijo. Todo esto influye en la manera en la que se relacionarán con este nuevo lugar, por lo cual se requiere del diseño de modelos de socialización y control social que permitan que el principio de realidad de cada residente esté por encima del principio del placer. Que la ley sea reguladora del deseo. 
El análisis de todos estos factores me motivó a plantear una metodología para la gestión social de la población vulnerable que habita en viviendas de interés social. Espero que este sea un aporte a la cultura de la convivencia social y a la mejora de la calidad de vida de la comunidad desde la fuente, es decir, desde el hábitat de cada persona, donde se da sentido al quehacer diario del individuo.

Como vimos a lo largo del presente documento, la metodología diseñada ha sido un éxito en la generación de cultura ciudadana y sostenibilidad de las viviendas para la población vulnerable donde logré implementarla (gracias al apoyo del sector privado, ya que sin ellos la financiación hubiese sido imposible).

Con la aplicación de esta metodología se demuestra que sí es posible mejorar las relaciones de vecindad entre residentes (de cualquier segmento socioeconómico y hasta con el mínimo grado de instrucción, como se evidenció en los dos diagnósticos socioeconómicos realizados para las 868 familias intervenidas). También es posible generar cultura ciudadana, mejorar la calidad de vida de toda la población e incrementar su patrimonio por medio de la valorización de sus viviendas gracias al mantenimiento y la conservación de los bienes comunes de sus conjuntos residenciales.

Es satisfactorio el nivel de aceptación, compromiso y participación de las familias intervenidas, ya que sin ellos no hubiera sido posible demostrar que se puede creer en la transformación de la sociedad a partir de su hábitat. Los resultados de los indicadores de gestión demuestran que en los dos casos tuvimos una participación en el proceso de formación y capacitación del $95 \%$ y del $90 \%$ de los hogares, además de la sostenibilidad económica de los conjuntos, es decir un pago de sus cuotas de administración o mantenimiento de servicios comunes del 91,2\% y del $100 \%$. También una administración y organización de órganos de control y dirección del $100 \%$ en los dos casos y un cumplimiento de los reglamentos de convivencia y normas internas del 99\%. Estos logros permiten evidenciar que más que medidas coercitivas o sancionatorias, lo que se requiere para lograr una sana convivencia, son mecanismos pedagógicos donde los ciudadanos, apelando a un proceso de socialización y control social, interioricen y practiquen el lema: "donde hay una sana convivencia, todos ganamos".

Los resultados superaron ampliamente mis expectativas iniciales, considero que en estos dos conjuntos aplica el refrán de "siembra vientos y recogerás tempestades”, porque las mejoras realizadas en el caso de Acanto (sistemas de seguridad, tienda comunal, bicicletero comunal, etc.) y Los Ceibos (mejora de zonas verdes, autoconstrucción de portería, acabados en zonas de circulación, iluminación de zonas comunes, sistema contra incendios, mejora del punto de acopio de basuras) demuestran el sentido de pertenencia de estas familias con su conjunto.

Pero esto no queda acá y es importante resaltar la participación de la comunidad como la organización del frente de seguridad, el festival de talentos culturales y los grupos musicales juveniles en Acanto; así como las jornadas de trabajo comunitarias para aseo e iluminación, el festival de comidas típicas y la organización de polladas para recolectar fondos para el mejoramiento en el caso de Los Ceibos.

Algo relevante en la aplicación de esta metodología es que permitió que estas dos constructoras entiendan que no se trata solamente de vender un proyecto, entregar una llave y que el cliente se las arregle como pueda; sino que al apoyar en la construcción de comunidad se hacen socialmente responsables. Si todos los constructores 
de vivienda se preocuparan por implementar un programa de acompańamiento social que genere competencias ciudadanas desde el hábitat, se impactaría en la construcción de mejores ciudades, mejor ciudadanía y mejores países; ya que, por ejemplo, solo en Bogotá el $65 \%$ de las construcciones están bajo el régimen de propiedad horizontal.

Hoy Acanto es un ejemplo a seguir en el macroproyecto más grande de Colombia: Ciudad Verde. Es un ejemplo de inclusión social y de Responsabilidad Social Empresarial.

Lo que se demostró con esta intervención es que sí se puede cambiar la cultura ciudadana en las comunidades y que debemos seguir apoyando desde el sector privado y público este tipo de iniciativas. Ejemplo de ello es el conjunto Los Ceibos, que son un modelo en Perú y el año pasado ocuparon el segundo lugar en el concurso de conjuntos en Lima.
Para finalizar, espero que estas iniciativas ayuden a que se cumpla lo que dijo nuestro nobel fallecido Gabriel García Márquez en su texto "Por un país al alcance de los niños":

[...] que nos inspire un nuevo modo de pensar y nos incite a descubrir quiénes somos en una sociedad que se quiera más a sí misma. Que aproveche al máximo nuestra creatividad inagotable y conciba una ética - y tal vez una estética - para nuestro afán desaforado y legítimo de superación personal [...]. Que canalice hacia la vida la inmensa energía creadora que durante siglos hemos despilfarrado en la depredación y la violencia, y nos abra al fin la segunda oportunidad sobre la tierra [...] (1994, p. 61).

\section{Bibliografía}

Centro de estudios y análisis de convivencia y seguridad ciudadana. (2014). Informe de Contravenciones, querellas y decomisos inspecciones de Policía Bogotá D. C. Comparativo 20132014. Recuperado de https://www.google.com. $\mathrm{co} / \mathrm{url}$ ? $\mathrm{sa}=\mathrm{t} \& \mathrm{rct}=\mathrm{j} \& \mathrm{q}=\&$ esrc $=\mathrm{s} \&$ source $=\mathrm{we}-$ $\mathrm{b} \& \mathrm{~cd}=1 \& \mathrm{cad}=\mathrm{rja} \&$ uact $=8 \& \mathrm{ved}=0$ ahUKEwi bzPnwivHOAhXSdSYKHfO-BDMQFggcMAA\&url=http\%3A\%2F\%2Fwww.ceacsc. gov.co $\% 2$ Findex.php $\% 2$ Fdescargas $1 \% 2 \mathrm{~F}$ category $\% 2 \mathrm{~F} 24$-querellas-y-contravenciones\%3Fdownload\%3D26\%3Aquerellas-y-contravenciones\&usg=AFQjCNGd_q6X2c9CQbvrZgSMoaLOil8AEQ\&sig2=aY9v4-UiTRmnsBo3Onlg9Q

El Espectador. (22 de marzo de 2015). Agresiones y amenazas, lo que más afecta la convivencia entre vecinos en conjuntos residenciales. El Espectador. Recuperado de http://www.elespectador.com/noticias/bogota/agresiones-y-amenazas-mas-afecta-convivencia-entre-veci-articulo-550876

Freud, S. (1970). El malestar en la cultura y otros ensayos. Madrid: Alianza. 
García, G. (23 de julio de 1994). Por un país al alcance de los niños. El Tiempo. Recuperado de http://www.eltiempo.com/archivo/documento/ MAM-179534

Martin, I. (1997). Psicología social desde Centroamérica: acción e ideología: San Salvador: UCA Editores.

Parsons, T. (1968). La estructura de la acción social: estudio de teoría social, con referencia a un grupo de recientes escritores europeos. Madrid: Guadarrama. 